$\underline{\text { articles }}$

\title{
Understanding and Predicting Indian Restaurant Owners' Intention to Continue Business in Post-COVID-19 Pandemic Lockdown
}

\author{
R.K. Jena ${ }^{1}$ a \\ 1 Institute of Management Technology, Nagpur, India \\ Keywords: self-determination theory, theory of planned behavior, restaurant owner, India, COVID-19 \\ https://doi.org/10.53703/001c.32409
}

Journal of Small Business Strategy

Vol. 32, Issue 1, 2022

\begin{abstract}
Restaurant business is one of the profit making and employment generation small scale businesses in India. Restaurant owners are on the verge of losing their businesses and suffering from different psychosocial stress due to COVID-19 lockdown. Therefore, this study explores the restaurant owners' intention to sustain their business after the COVID-19 lockdown. This study has adopted an integrated model that combines the theory of planned behaviour (TPB) and the self-determination theory (SDT) to predict behavioural intention. ' 566 ' participants from eight different cities of central India participated in the study. The results confirmed that the motivational factors (need satisfaction (NS) and need frustration (NF)) significantly influence the attitude (AT), subjective norms (SN), perceived behavioural control(PBC) and behavioural Intention (BI). The findings have also established the partial mediating effect of AT, SN, PBC on the relationship between motivational construct (NS \& NF) and BI. The findings may help all the stakeholders to support the restaurant owners in their pursuit to continue business after the COVID-19 lockdown.
\end{abstract}

\section{Introduction}

The world witnessed the COVID-19 pandemic in December 2019. During the last six months, it has spread over more than 200 countries in the world. Its unexpected appearance caused misperception, nervousness and distress among people all over the globe. In due course, World Health Organization (WHO) declared COVID-19 as a Public Health Emergency of International Concern on 30 January 2020 (WHO, 2020). But the lack of appropriate protective measures and medication facilities are the primary cause of concern among the general public. Further, the situation in India is bleak due to its demography and dense population. The degree of panic is also high in public due to the lack of proper healthcare facilities. The government has taken various steps to prevent the community level spread of COVID-19. The government of India declared the first phase of nationwide total lockdown from 25 March 2020. The lockdown has crushed multiple industries, and the most affected sector is the tourism and hospitality industry (Rivera, 2020; Sigala, 2020). The restaurant industry is the most affected sector as it thrives on the social gathering. Restaurant business has been hampered due to the imposition of social distancing norms by the authorities. In addition to the above, the industry in India works on a slim 10\%-15\% Earnings Before Interest, Taxes, Depreciation, and Amortization (EBITDA) margins and with barely two- three weeks of cash flow in hand (Mehrotra, 2020). The restaurant industry is also one of the largest service sectors in India. With an annual turnover of Rs 4.25 lakh crore, this industry contributes around 3\% to India's GDP (NRAI, 2020). It is also the single largest employer with more than 73 lakhs people working for their livelihood. In their survey, the National Restaurant Association of India Industry (NRAI) has estimated that one in every four restaurants in India may never open again. In addition, NRAI has also estimated that over twenty-two lakh people will lose jobs, and the total losses will touch the one lakh crore INR mark. Even if the lockdown is lifted, this industry would never be able to work as before. This is because this industry needs more resources to implement the safety guidelines and making customers feel safe. Restaurants in Singapore, China, and South Korea, which had recently open after the COVID-19 lockdown, face similar problems. All these new, unexpected cost-related issues would land a severe blow to the restaurant's bottom line. The situation is even worse in India, as the average dining out is only 4.1 per month (NRAI, 2020).

Even after the lockdown, the situation and environment will never be the same. The first and foremost challenge that restaurants will face after the COVID-19 pandemic is customer behaviour change. With a rise in conscious consumers, restaurants must maintain the utmost hygiene and adopt digital services to sustain the business. All the extra resources required for the same would impact their 
turnover. My research team got an opportunity to meet 8-10 restaurant owners during the first phase of lockdown to understand their future concerns and plans. They were all psychologically disturbed and very unsure about their future endeavours. Therefore it was decided to undertake this study to assess the restaurant owner's intention to continue with their businesses after the COVID-19 lockdown.

On the other hand, various studies have ascertained that intention is the best antecedent of voluntary behaviours (Ajzen, 1991; Al-Jubari, 2019). For that reason, to understand and predict the behavioural intention to sustain the restaurant business during and after COVID-19, it was essential to understand the restaurant owner's entrepreneurial thought process. Therefore the Theory of Planned Behavior (TPB) was adopted to predict the intention as it laid down the basic premises of understanding the antecedents of behavioural Intention (Ajzen, 1991). But, the TPB does not explain why any behaviour is followed to predict Intention (Al-Jubari, 2019; Deci \& Ryan, 2012). During the same time, many researchers have found the utility of selfdetermination theory (STD) to explain the above reasons (Al-Jubari, 2019; Hagger \& Chatzisarantis, 2009). SDT can explain the usefulness of TPB constructs to predict behavioural Intention (Andersen et al., 2000). Therefore, this study exploited an integrated approach by combining the motivational constructs of SDT and cognitive, attitudinal constructs of TPB to provide a deep understanding of the antecedent of behavioural intention. The main contribution of this study is to understand how the basic "psychological needs" constructs can explain the creation of attitudes, subjective norms, and perceptions of self-capabilities towards a behavioural intention for entrepreneurial activities in a pandemic situation. Hence this research seeks to address the following research questions: "(1) Does basic psychological needs construct influence behavioural intention (BI) directly?; “(2) Do TPB factors mediate between basic psychological needs factors and BI relationships”. The results of this study can provide helpful information to the different stakeholders to motivate restaurant owners to continue with their business after the COVID-19 pandemic in India. Hence, the answer the research questions, the following objectives are underlined for this study:

- To inspect the role of restaurant owners' basic psychological needs in enhancing their entrepreneurial attitudes, subjective norms, perceived control behaviour and intentions to sustain their business after COVID-19 lockdown.

- To scrutinize the interceding effect of the three important cognitive constructs (attitude, subjective norms and perceived control) on the relationship between basic psychological needs and intention to sustain the business.

The rest of the paper is organized as follows: Past literature summarizing the theoretical background of TPB and SDT is discussed in the literature survey section. Then a theoretical explanation of integrating TPB and STD are discussed in the theoretical framework section. After that, the details of methodologies are presented in the methodology section. Subsequently, the results are analyzed and discussed in the result analysis and discussion section, respec- tively. Finally, the study is concluded with a conclusion, limitation and future direction.

\section{Theoretical Framework}

The restaurant business is one of the profit-making small business ventures in India. Recently, the industry has suffered due to the COVID-19 pandemic lockdown. Recently, different studies have identified and discussed many difficulties faced by the restaurant industries due to the pandemic (Jaewook Kim et al., 2020; Jungkeun Kim \& Lee, 2020). Restaurant owners in India are suffering both financially and psychologically. Therefore, to predict their intention to sustain their businesses after COVID-19 lockdown was the primary agenda of this study. The use of psychological characteristics to predict and explain human intention is not new in the research arena. Several research studies have addressed the issues related to different human psychological dimensions for understanding the antecedents, which energizes the individuals to make future decisions. By the way, amongst the most commonly used theoretical frameworks, TPB and SDT are being used extensively in predicting future entrepreneurial behaviour (Al-Jubari, 2019; Shin et al., 2018). More details about these theories are being discussed in the following sections.

\subsection{Theory of Planned Behavior (TPB)}

The Theory of Planned Behavior (TPB) has been recognized as a framework to predict individuals' intention to engage in a behaviour at a specific place and time. Several other theoretical frameworks also exist in the literature, but the advantage of TPB has been recognized by several researchers (Al-Jubari, 2019; Fayolle et al., 2014; Shin et al., 2018). The theoretical framework of TPB considers the personal factors and includes the individual's social and environmental factors. Originally, TPB encompassed six constructs (attitudes, subjective norms, social norms, perceived power and perceived behavioural control, and behavioural intention) to represent a person's actual control over a behaviour collectively. But, past studies have established that behavioural intention is mainly determined by three conceptually independent antecedents, e.g. attitudes (AT) toward the behaviour, subjective norms (SN), and perceived behavioural control (PBC) (Liao \& Fang, 2019).

\section{Behavioural Intention}

Behavioural intention is one of the significant constructs used in this study. Individuals' behavioural intentions are usually influenced by factors, e.g. attitude towards behaviour, subjective evaluation of the risks and benefits of the expected outcomes, perception of one's ability to perform the behaviour and motivations. As such, intention to set up a new business or sustain an existing business refers to "as a self-acknowledged conviction to set up a new business venture and consciously plan to do so at some point in the future" (Thompson, 2009). Some researchers also believe that behavioural intention can be better understood due to its underlined theoretical framework (Radel et al., 2017). The three significant constructs of TPB (attitude, subjective norms, and perceived behavioural control) have been found 
to have a significant influence on behavioural intentions (Liñán \& Chen, 2009). On the other hand, the motivational factors of SDT also have a significant impact on behavioural intentions (Liao \& Fang, 2019; Radel et al., 2017). The detailed justification of the relevant constructs of TPB and STD and their relationship to predict the restaurant owners' behavioural intention to sustain their business is being discussed next.

\section{Attitude towards Behaviors}

The attitude towards a behaviour refers to the people's overall evaluation (positive or negative) or assessment of the behaviour under study (Ajzen, 1991). That means before forming any intention, people seem to form their views in favour or against a behaviour. People show their favourable attitude towards a behaviour when they perceive it to have desirable consequences (Fregetto, 2015). The attitude construct of TPB has shown a reliable and robust influence on behavioural intention in several studies in various cultural settings (Almobaireek \& Manolova, 2012; Chaulagain et al., 2021; Liao \& Fang, 2019). But, some studies have also reported contradictory results (Siu \& Lo, 2013). In their study, Siu \& Lo (2013) found that attitude failed to predict intention to start a new business in a collectivist context. Based on the discussion, the following hypothesis is proposed:

H1a: The attitude significantly predicts the restaurant owners' intention to sustain the business after the COVID-19 lockdown

\section{Subjective Norms}

Subjective norms(SN) refer to “a person's beliefs on how and what to think about the people who are considered important motivators to complete the task" (Ajzen, 1991). Primarily SN based on two types of beliefs: normative belief and motivation to comply. The normative component ensures whether the support environment would approve or disapprove of their behaviour, such as continuing a business after the pandemic. The motivation to comply believes in behaving according to the expectations and adhering to the norms (Ajzen, 1991). Past studies have also used SN to predict BI. But the findings are not consistent. For example, some studies have been reported as insignificant or the least significant antecedents of BI (Almobaireek \& Manolova, 2012).

On the contrary, other studies have shown the strong predictive power of SN to predict BI (Iakovleva \& Kolvereid, 2009; Siu \& Lo, 2013). But, in a pandemic situation, restaurant owners may seek advice and support from people around them. As a result, their intention to continue with business would influence such advice (Van den Broeck et al., 2008). Based on this literature, the following hypothesis is formulated:

$H 1 b$ : The Subjective norms significantly predicts the restaurant owners' intention to sustain the business after the COVID-19 lockdown

\section{Perceived Behavioural Control}

Perceived behavioural control(PBC) is another crucial constituent of the TPB framework. It can be defined as "the factor, which measures the perceived easiness or difficulty in performing the behaviour, and it assumes to reflect past experiences as well as anticipates the impediment and obstacles" (Ajzen, 1991). Ajzen (1991) states that "These control beliefs may be based in part on experience with the behaviour, but they will usually also be influenced by secondhand information about the behaviour, by the experiences of acquaintances and friends, and by other factors that increase or reduce the perceived difficulty of performing the behaviour in question. (p. 196)”. PBC factors can be assumed a reflection of past experiences and anticipation of obstacles towards intention. Past studies have established the significant relationship between PBC and BI in a different domain (Almobaireek \& Manolova, 2012). PBC has shown some differences in predicting Intention in various contexts (Kautonen et al., 2013; Moriano et al., 2012). Hence the following hypothesis is posited:

H1c: The Perceived Behavioural Control significantly predicts the restaurant owners' intention to sustain the business after the COVID-19 lockdown

The TPB models have been successfully adopted in various fields to predict and elucidate a wide range of behavioural intentions (Al-Jubari, 2019; Kautonen et al., 2013). But, the TPB does not differentiate between the beliefs and the assessment of the behavioural outcomes (Al-Jubari, 2019; Hagger \& Chatzisarantis, 2009). That is, TPB doesn't distinguish the fact that "do people engage in a behaviour because they choose to or because they are compelled to?" Hence, TPB alone can't explain the antecedents of behavioural intentions. Therefore, SDT was used along with TPB to clarify and justify the antecedents to the behavioural Intention (Al-Jubari, 2019; Andersen et al., 2000; Roca \& Gagné, 2008).

\subsection{Self-Determination Theory (SDT)}

Self-determination theory (SDT) is primarily related to human motivation. SDT suggests that every individual have motivations for growth and accomplishment. These natural human tendencies can be influenced by different social settings (Deci \& Ryan, 2000). There are mainly three core concepts revolving around SDT. First, SDT claims that every individual has three psychological needs, e.g. competence, autonomy and relatedness. All these needs are essential to function efficiently and mature psychologically (Deci \& Ryan, 1985). Secondly, SDT differentiates between intrinsic and extrinsic motivations. Extrinsic motivation involves outcomes; for example, pride, prestige and receiving wealth or even avoiding joblessness can influence extrinsic motivation. Intrinsic motivation, on the other hand, reflects an individual's interest and enjoyment. The social environment is the third facet of SDT. The social environment can be observed as either supportive or not supportive. The supportive social environment centres on the belief that needs can be satisfied using autonomous actions.

On the other hand, an unsupportive social environment holds that people feel controlled, resulting in low-quality performance (Deci \& Ryan, 2012). There are different subtheories, which have been revolving around SDT. One of the essential sub-theories of SDT is the Basic psychological Needs Theory (BPNT). It talks about humans' basic needs to 
pursuing their behavioural Intention (Cardella et al., 2020; Chen et al., 2015; Deci \& Ryan, 1985, 2000). These needs (e.g. autonomy, competence and relatedness) are applicable in all human life dimensions and universal across people and cultures (Milyavskaya \& Koestner, 2011). Autonomy refers to the insight that one's behaviour is self-consistent and volitional (Milyavskaya \& Koestner, 2011). Autonomy is essential to initiate, maintain, and terminate the behavioural engagement. The construct 'competence' refers to peoples' perceptions. It can influence the situation in favourable directions. The perception of competence to complete a task is characterized by the task difficulties and defies. Relatedness comprises connectedness and intimacy with others in diverse environments (Weinstein \& Ryan, 2011). Satisfaction of the "need for relatedness" facilitates the process of internalization. All the above discussed psychological needs influence the individuals' behavioural intention across numerous domains.

As discussed, need satisfaction influences intrinsic motivations and need frustration impacts extrinsic motivations. Further, two constructs of SDT, i.e. need satisfaction and need frustration, have been found to influence the attitude, subjective norms and perceived behavioural Control (Teixeira et al., 2018). Various studies have also shown the utility of Need satisfaction and Need frustration as an antecedent to behavioural Intention (Al-Jubari, 2019; Hagger \& Chatzisarantis, 2009). Thus the following hypotheses are postulated:

H2: Psychological need satisfaction significantly influence (direct) the attitude (H2a), subjective norms (H2b), perceived behavioural control (H2c) and behavioural Intention (H2d).

H3: Psychological need frustration significantly linked (direct) to the attitude ( $\mathrm{H} 3 \mathrm{a})$, subjective norms ( $\mathrm{H} 3 \mathrm{~b})$, perceived behavioural control (H3c) and behavioural Intention (H3d).

\subsection{Integration of SDT and TPB}

Pursuing and creating entrepreneurial activity is primarily influenced by intentional and purposeful behaviour. To understand the motivation and cognitive processes involved in this behaviour towards sustaining the business, integrating the theory of motivation (SDT) with the social cognitive theory (TPB) appear to be more suitable (AlJubari, 2019; Hagger \& Chatzisarantis, 2009). Combining both theories can be helpful to study the intention towards a behaviour more deeply because they are thought to "provide complementary explanations of the processes that underlie motivated behaviour" (Hagger \& Chatzisarantis, 2009). The integration of TPB and SDT is not a new approach. Previous studies have successfully integrated both the theories in various domains, mainly in health and sport studies (Chaulagain et al., 2021). Li \& Wu (2019), in their study, found that the integrated model explained the voluntary retention to continue the act better than only use SDT or the TPB. Hagger \& Chatzisarantis (2009) have integrated SDT motivational constructs (autonomy, competence and relatedness) and the perceptual factors of the TPB (AT, SNs and PBC) to predict entrepreneurial intentions. They argued that integrating SDT andTPB can help to understand the quality of behaviour in entrepreneurial activities. Further, Barkoukis et al. (2010) observed that the

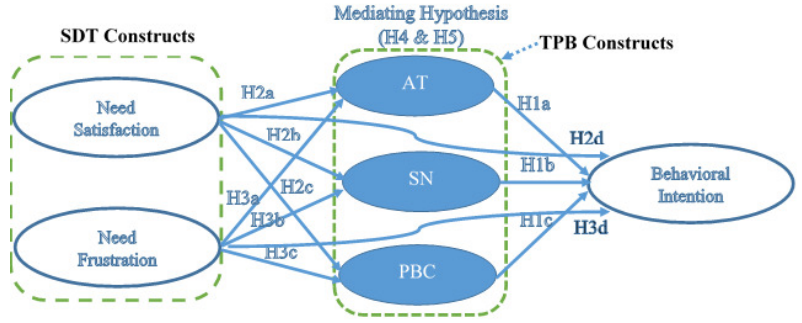

Figure 1. Proposed Framework

basic psychological need constructs (e.g. autonomy, competence and relatedness) exclusively predict the autonomous intention. Another study by Hagger \& Chatzisarantis (2009) found that self-controlled motivation predicts intentions to engage in behaviour and is significantly mediated by the TPB constructs (e.g. AT \& PBC). Roca \& Gagné (2008) have tested the applicability of SDT to clarify the role of both intrinsic and extrinsic motivation in the acceptance of elearning. Their findings also showed that when people felt autonomous and competent (i.e. basic needs are satisfied), they are more excited to continue using IT.

The framework has proposed three proximal antecedents of intention, i.e. attitude (AT), social norms (SN) and perceived behavioural control (PBC), to predict behavioural intention. But, as discussed, TPB does not distinguish between self-determined outcomes and controlled outcomes to predict Intention (Hagger \& Chatzisarantis, 2009). Therefore, motivational factors of SDT is used to explain the perpetual constructs of TPB (Al-Jubari, 2019; Andersen et al., 2000). The SDT need constructs, e.g. need satisfaction and frustration, predict TPB constructs and behavioural intention. The need satisfaction and need frustration constructs are derived from the individuals' psychological needs (e.g. autonomy, competence and relatedness).

Further, various studies have found the usefulness of integrating SDT and TPB to understand better and differentiate the different antecedents of behavioural Intention (AlJubari, 2019; Chaulagain et al., 2021; Li \& Wu, 2019). All these studies have also established the mediating role of AT, NS and PBC in predicting behavioural intention from psychological need constructs. Based on the information gained from the past studies regarding the integration of TPB and SDT, the following hypotheses are framed:

H4: The association between need satisfaction and intention to sustain the owned business after COVID-19 lockdown is mediated by the attitudes toward owned business (H4a), subjective norms (H4b) and perceived behavioural control (H4c).

H5: The association between and need frustration and intention to sustain the owned business after COVID-19 lockdown is mediated by the attitudes toward owned business (H5a), subjective norms (H5b) and perceived behavioural control $(\mathrm{H} 5 \mathrm{c})$.

\section{Design Methodology}

\subsection{Study Instrument}

This study has adopted a questionnaire-based data collection method. The questionnaire was divided into three 
Table 1. Participants' demographic information

\begin{tabular}{|l|l|l|}
\hline \multirow{2}{*}{ Variables } & Categories & Number \\
\hline \multirow{2}{*}{ Age } & \multirow{2}{*}{ Male } & 429 \\
\cline { 2 - 3 } & Female & 137 \\
\hline \multirow{2}{*}{ Education } & Below 35 & 213 \\
\cline { 2 - 3 } & Above 35 & 353 \\
\hline \multirow{2}{*}{ Number of years in Restaurant Business } & Graduate and below & 378 \\
\cline { 2 - 3 } & Above Graduation & 188 \\
\hline \multirow{2}{*}{ Employee Strength } & Ten years and below & 262 \\
\cline { 2 - 3 } & Above 10 years & 304 \\
\hline
\end{tabular}

sections. The first part was used to explain the purpose of this study to respondents. The second part of the questionnaire was designed to measure the constructs used in this study. Each concept/construct was clearly defined to facilitate correct understanding. The last section of the questionnaire was devoted to collect the participants' demographic information.

All constructs of the proposed model were measured by research instruments adapted from previous studies. The scales for attitude toward behaviour, subjective norm, perceived behavioural control, and the behavioural intention was modified from Al-Jubari (2019). Attitude toward behaviour was measured using a 4-items scale. An example of questions like "I'm determined to continue with my business in the post-COVID-19" was part of the scale. A 3-items scale measured the subjective norm. For example, an item like "My immediate family would approve my decision to continue with my business" was included in the scale. Perceived behavioural control was measured using a 4-items scale. An item like "Re-starting a business and keeping it working would be easy for me" was mentioned in the scale. The behavioural intention scale was measured using three items. The basic psychological need satisfaction and frustration scale were adapted from Deci \& Ryan (1985). The need satisfaction scale consisted of 12 items measuring autonomy, competence, and relatedness. Similarly, the need frustration scale was consisting of 12 items measuring the frustration aspects of autonomy, competence and relatedness. The sample item for the need satisfaction was "I feel competent to achieve my goals even after COVID-19 lockdown”. Similarly, the sample item for need frustration was "I feel like a failure because of the hardship I faced during COVID-19 lockdown”. All the items were measured using a 5-points Likert scale.

As the scales were primarily adapted from western studies, a pilot study was conducted to assess and improve the questionnaire reliability in the Indian context. In the pilot test, forty completed questionnaires were collected from restaurant owners belongs to Nagpur, India. The reliability scores (Cronbach's alpha) of all the constructs were more than 0.7. Thus, the used instrument was found reliable and usable for data collection.

\subsection{Participants}

A cross-sectional survey based on a stratified sampling procedure was used for data collection. The stratification sampling method can increase the preciseness of statistical estimates (Creswell \& Creswell, 2017). A total of 1,100 restaurant owners (small and medium scale) from eight different Tier-II and Tier-III cities (i.e., Nagpur, Raipur, Durg, Sambalpur, Bilaspur, Rourkela, Indore and Bhopal) spreading over four states from central India participated in this survey during April 2020 and September 2020. Initially, all the participants' contact details were collected from yellow pages, Swiggy, and Uber-eats websites of the respective cities. All participants were informed about the survey objectives and assured that their responses would be used only for research purposes. A total of 609 responses were collected, yielding a response rate of around $53 \%$, which is acceptable in social science researches (Hair et al., 2010). Subsequently, 43 incomplete responses were removed. The remaining ' 566 ' valid responses were used for data analysis.

The participants' demographic information is shown in Table 1. According to the data, the mean age of the participants is approx. 43 years. Approximately $24 \%$ of the participants are women. Most of the participants' educational qualification is undergraduate. In addition, more than 50\% of the respondents have more than ten years of experience in the restaurant business. The average employee strength of the restaurant is approximately fourteen in numbers.

\section{Data Analysis}

A structural equation modelling (SEM) technique based on a partial least squares (PLS) regression was used for model validation and hypothesis testing. PLS-SEM is a variance-based and robust second-generation SEM technique (Deci \& Ryan, 2000; Fachrunnisa et al., 2020). PLS-SEM can cope with complex structural models and reduce measurement errors (Hair et al., 2017). PLS-SEM techniques suites the nature of the present study (Hair et al., 2017). R packages (Lavaan and sem2) were used for PLS-SEM. Furthermore, to ensure the data quality and several data screening processes for missing values and outliers, a common- 
Table 2. Construct Reliability and validity

\begin{tabular}{|l|l|l|l|l|l|}
\hline Constructs & $\begin{array}{l}\text { No. of } \\
\text { items }\end{array}$ & $\begin{array}{l}\text { Item } \\
\text { loading }\end{array}$ & $\begin{array}{l}\text { Cronbach's } \\
\text { Alpha }\end{array}$ & $\begin{array}{l}\text { Average } \\
\text { VarianceExtracted } \\
\text { (AVE) }\end{array}$ & $\begin{array}{l}\text { Composite } \\
\text { Reliability (CR) }\end{array}$ \\
\hline Attitude (AT) & 4 & $0.72-0.86$ & 0.77 & 0.65 & 0.81 \\
\hline Subjective Norms (SN) & 3 & $0.66-0.91$ & 0.75 & 0.64 & 0.78 \\
\hline $\begin{array}{l}\text { Perceived Behavioral } \\
\text { Control (PBC) }\end{array}$ & 4 & $0.70-0.89$ & 0.77 & 0.63 & 0.81 \\
\hline Need Satisfaction(NS) & 12 & $0.62-0.82$ & 0.72 & 0.66 & 0.79 \\
\hline Need Frustration(NF) & 12 & $0.64-0.85$ & 0.73 & 0.62 & 0.78 \\
\hline Behavioral Intention (BI) & 3 & $0.73-0.83$ & 0.76 & 0.67 & 0.78 \\
\hline
\end{tabular}

method variance test and a nonresponse bias test were performed.

\subsection{Nonresponse Bias Test}

As previously mentioned, a self-administered instrument was used for data collection. Therefore, it was essential to investigate whether any potential nonresponse bias existed in the collected data. An extrapolation method suggested by Armstrong and Overton (Armstrong \& Overton, 1977) was employed to check the potential nonresponse bias. This approach compared and analyzed the responses of both early respondents and late respondents to identify any potential variance in their mean values (Armstrong \& Overton, 1977). A $t$-test was performed to compare the mean values of the first 150 participants with those of the last 150 participants. Based on the test result, no significant variance $(t=11.4 ; p<0.01)$ was observed in the mean values of the samples. Hence, the collected data was free from nonresponse bias.

\subsection{Common-Method Variance Test}

In cross-sectional studies, common-method variance is a severe problem (Hair et al., 2017). Therefore, to address the common-method variance problem in this study, the method devised by (Podsakoff, 2003) was used. Based on Harman's guidelines (Harman, 1976), a one-factor test was conducted for all ' 38 ' items as one factor, using a varimax rotation approach. The outcomes of the one-factor test yielded six different factors (i.e., NS, NF, AT, SN, PBC, BI) and converged after six iterations. The total variance explained by the test was $37 \%$, which falls well below the threshold of 50\% (Harman, 1976). These findings confirmed that the "common method variance" did not appear to be a significant factor in this research.

\subsection{Model Evaluation}

Initially, the first- and second-order CFA were performed to assess the factor binding before testing the proposed model. First-order CFA was applied to need motivation scales. Each item was specified to load on its respective priority constructs (relatedness need satisfaction and frustration, autonomy need satisfaction and frustration, and com- petence need satisfaction and frustration). Second, these first-order factors were specified to load on a higher-order model, i.e. need satisfaction and need frustration (Table 2). All-fit indices of the model were found acceptable $\left(\chi^{2}=451.89, \mathrm{df}=324, \mathrm{CFI}=0.969, \mathrm{TLI}=0.987\right.$, and $\mathrm{RM}-$ $\mathrm{SEA}=0.039)$. After factor confirmation, it is recommended to determine the reliability and validity of the constructs (convergent and discriminant) before structural model testing.

\subsubsection{Construct Reliability and Validity}

The construct validity and reliability of the proposed model were evaluated using internal reliability (IR), convergent validity (CV), and discriminant validity (DV). Cronbach's alpha and composite reliability (CR) were used to determine the IR of the constructs. The average variance extracted (AVE) was used to assess the CV of the construct. The item loading range, Cronbach's alpha, AVE, and CR values are listed in Table 2.

The results presented in Table 2 demonstrate the reliability and construct validity of all the proposed constructs. The estimated construct loadings are ranged from 0.62 to 0.91 . All of the loadings are higher than the recommended values (Hair et al., 2017). The construct reliability was measured by Cronbach's alpha and CR score (Table 2). The values of Cronbach's alpha are ranged from 0.72 to 0.77 , and the values of the CR are ranged from 0.78 to 0.81 . The Cronbach's alpha and CR values of each construct in the proposed model exceed the recommended cutoff of 0.7 (Hair et al., 2017). This implies that each construct under consideration has exhibited a high level of reliability and consistency. The AVE ranges from 0.62 (need frustration) to 0.67 (behavioural intention), and the AVE value of each construct is higher than 0.5 (Hair et al., 2017), thereby establishing a high CV for all the constructs.

Furthermore, to determine the DV of each construct, the square root of the AVE for each construct was compared with its inter-construct correlation. To achieve satisfactory $\mathrm{DV}$, the square root of the AVE of each construct should be higher than its correlation with other constructs (Hair et al., 2010). This means that the central diagonal values must be greater than the off-diagonal values in Table 3 (Henseler et al., 2009). The results in Table 3 shows that for each construct, the square root of the AVE (shown diagonally with 
Table 3. Constructs Discriminant Validity

\begin{tabular}{|l|l|l|l|l|l|l|l|l|}
\hline Construct & Mean & SD & AT & SN & PBC & NS & NF & BI \\
\hline AT & 3.29 & 0.23 & 0.80 & & & & & \\
\hline SN & 3.12 & 0.71 & $0.46^{*}$ & 0.77 & & & & \\
\hline PBC & 2.91 & 0.46 & $0.44^{*}$ & $0.33^{*}$ & 0.79 & & & \\
\hline NS & 3.18 & 0.61 & $0.41^{*}$ & $0.42^{*}$ & $0.35^{*}$ & 0.81 & & \\
\hline NF & 2.83 & 0.74 & $0.33^{*}$ & $0.37^{*}$ & $0.33^{*}$ & $-0.32^{*}$ & 0.79 & \\
\hline BI & 3.17 & 0.68 & $0.46^{*}$ & $0.44^{*}$ & $0.42^{*}$ & $0.45^{*}$ & $0.37^{*}$ & 0.82 \\
\hline
\end{tabular}

$* \mathrm{p}<0.05$

bold values) is higher than the inter-construct correlation. Therefore, all of the constructs are satisfied with the required level of DV.

\subsection{Structured Model Assessment}

The proposed hypotheses were tested using PLS regression. The goodness of fit (GoF), path coefficient, and coefficient of determination $\left(\mathrm{R}^{2}\right)$ were used to assess the overall quality of the proposed model. The GoF was determined by the geometric mean of the average commonality and average $\mathrm{R}^{2}$ value $\left(\mathrm{GoF}=\sqrt{\overline{\mathrm{AVE}} * \overline{R^{2}}}\right)$ as suggested by Alolah and colleagues (2014). The recommended threshold value of GoF is 0.36 (Alolah et al., 2014). The GoF value for the proposed model was 0.68 , which is more than the threshold values. Therefore, the overall quality of the model was satisfactory. Further, the relationships between the dependent and independent variables were tested using the path coefficient and t-statistics. The bootstrapping resampling method was used to determine the coefficients (the number of iterations was fixed at 1,000).

The hypotheses concerning the direct relationship between AT, SN, PBC, NS, NF and BI are shown in Table 4. Considering AT as a dependent variable, the direct effect of need satisfaction (NS) and need frustration (NF) are significant, with path coefficients of 0.38 and 0.26 , respectively. This demonstrates that need satisfaction and frustration positively influence restaurant owners' attitudes towards their own business even after COVID-19 lockdown. Hence, hypotheses H1a and H2a are confirmed. Similarly, both need satisfaction and frustration to positively impact the subjective norm (path coefficient of 0.32 and 0.24 , respectively). Hence hypotheses $\mathrm{H} 1 \mathrm{~b}$ and $\mathrm{H} 2 \mathrm{~b}$ are also supported.

Further, need satisfaction (0.41) and need frustration (0.32) positively influenced the perceived behavioural control towards their owned business. Therefore H1c and H2c are supported. Further from the results, there is a significant direct effect of need satisfaction (0.23) and need frustration (0.14) on behavioural intention. Thus, hypothesis (H2d) and (H3d) is supported. The above hypothesis results are confirmed the direct effect of independent variables on their respective dependent variables. From the above hypothesis test results, it is also observed that motivational factors like need satisfaction and need frustration positively influence attitude, subjective norms, and perceived behavioural control and behavioural intention. Hence SDT con- structs (NS \& NF) are proved as an antecedent to AT, NS, $\mathrm{PBC}$ and $\mathrm{BI}$.

Furthermore, from Table 4, it is observed that the behavioural intention towards sustaining the restaurant business is positive influenced (significant) by attitude towards owned business (0.41), subjective norms (0.36) and perceived behavioural control (0.39). Hence hypotheses H3a, $\mathrm{H} 3 \mathrm{~b}$ and $\mathrm{H} 3 \mathrm{c}$ are supported. That means attitude, subjective norms and perceived behavioural control are proven positive antecedents of behavioural intention towards sustaining business in post-COVID-19 lockdown.

So far, from the above findings, it is observed that the proposed structural model has a significant explanatory power (i.e. $\mathrm{R}^{2}$ value is 0.68 ). But, the researchers have ascertained that only $\mathrm{R}^{2}$ is not sufficient to assess the stinginess of a structural model in the PLS-SEM approach (Hair et al., 2017). So, the predictive power of the proposed model was estimated using Stone-Geisser's $Q^{2}$ test (Stone, 1974). The $\mathrm{Q}^{2}$ value was calculated by using the Blindfolding procedure. $Q^{2} \neq 0$ indicates a significant predictive relevance for its endogenous variables (Hair et al., 2017). The $Q^{2}$ value of the proposed model was found at 0.31 , which indicates a strong predictive relevance for restaurant owners' intention towards continuing the business after COVID-19. After testing the direct impact of the independent variable to their respective dependent variable, the following sub-section is aimed to explore the mediation effect of AT, SN, PBC on the relationship between psychological need constructs (NS and NF) and behavioural intention.

\subsubsection{Mediation Effect}

One of the most important objectives of this study was to assess the mediating effects of attitude, subjective norms, and perceived behavioural control in the relation between need constructs (need satisfaction, need frustration) and the behavioural intention to sustain the owned business after COVID-19 lockdown among the restaurant owners in India. The proposed model is a complex model having multiple parallel mediations. Therefore, parallel multiple mediator models suggested by Singh and colleagues (Singh et al., 2014) was adopted. The mediation results are presented in Table 5, which have confirmed the mediating role of AT, SN, PBC in the relation between need constructs (NS, $\mathrm{NF}$ ) and behavioural intention to sustain the business. All the standard betas $(\beta)$ are found significant. Hence, the hy- 
Table 4. Path coefficients for direct effects

\begin{tabular}{|c|c|}
\hline Dependent Variable: Attitude (AT) & Direct Effect \\
\hline$R^{2}$ & 0.61 \\
\hline Adj. $R^{2}$ & 0.63 \\
\hline Need Satisfaction(NS) & $0.38^{*}$ \\
\hline Need Frustration(NF) & $0.26^{*}$ \\
\hline \multicolumn{2}{|l|}{ Dependent Variable : Subjective Norms (SN) } \\
\hline $\mathrm{R}^{2}$ & 0.57 \\
\hline Adj. $\mathrm{R}^{2}$ & 0.58 \\
\hline Need Satisfaction(NS) & $0.32^{*}$ \\
\hline Need Frustration(NF) & $0.24^{*}$ \\
\hline \multicolumn{2}{|c|}{ Dependent Variable: Perceived Behavioral Control (PBC) } \\
\hline $\mathrm{R}^{2}$ & 0.65 \\
\hline Adj. $R^{2}$ & 0.66 \\
\hline Need Satisfaction(NS) & $0.41^{*}$ \\
\hline Need Frustration(NF) & $0.32^{*}$ \\
\hline \multicolumn{2}{|c|}{ Dependent Variable: Behavioral Intention (BI) } \\
\hline $\mathrm{R}^{2}$ & 0.68 \\
\hline Adj. $R^{2}$ & 0.69 \\
\hline Attitude(AT) & $0.41^{* *}$ \\
\hline Subjective Norms(SN) & $0.36^{* *}$ \\
\hline Perceived Behavioral Control (PBC) & $0.39^{* *}$ \\
\hline Need Satisfaction (NS) & $0.23^{*}$ \\
\hline Need Frustration (NF) & $0.14^{*}$ \\
\hline
\end{tabular}

$* \mathrm{p}<0.05 ;{ }^{* *} \mathrm{p}<0.01$

Table 5. Indirect Effect

\begin{tabular}{|l|l|l|}
\hline Path & Standard Beta( $(\boldsymbol{)})$ & $\mathrm{t}$-value \\
\hline $\mathrm{NS} \rightarrow \mathrm{AT} \rightarrow \mathrm{BI}$ & $0.31^{*}$ & 6.89 \\
\hline $\mathrm{NS} \rightarrow \mathrm{SN} \rightarrow \mathrm{BI}$ & $0.17^{*}$ & 3.68 \\
\hline $\mathrm{NS} \rightarrow \mathrm{PBC} \rightarrow \mathrm{BI}$ & $0.21^{*}$ & 4.35 \\
\hline $\mathrm{NF} \rightarrow \mathrm{AT} \rightarrow \mathrm{BI}$ & $0.23^{*}$ & 5.01 \\
\hline $\mathrm{NF} \rightarrow \mathrm{SN} \rightarrow \mathrm{BI}$ & $0.16^{*}$ & 3.11 \\
\hline $\mathrm{NF} \rightarrow \mathrm{PBC} \rightarrow \mathrm{BI}$ & $0.21^{*}$ & 4.35 \\
\hline
\end{tabular}

* P $<0.01$ \& Critical t-values: 2.58

pothesis $\mathrm{H} 4$ and $\mathrm{H} 5$ are supported.

From the above results (Table 5), even the mediations are confirmed, through investigations are required to validate the mediation and assess the size of mediation (full $\backslash$ partial). Therefore, Preacher and Hayes' bootstrapping approach (Preacher \& Hayes, 2008) along with Sobel's test for mediation (Sobel, 1982) were used to assess the types of indirect effects between (NS, NF) and BI, via attitude, subjective norms, and perceived behavioural control. To assess the quality of the mediating effect, first, the direct effect of (NS, NF) $\rightarrow$ BI was assessed without including the media- tors. The findings are presented in Table 6 . The results have revealed that both NS and NF have a significant direct effect on $\mathrm{BI}$ without a mediator $(\beta=0.52 ; t$-value $=21.56$ for $\mathrm{NS} \rightarrow \mathrm{BI} ; \beta=0.34 ; t$-value $=14.09$ for $\mathrm{NF} \rightarrow \mathrm{BI}, \mathrm{p}<0.01$ ).

Further, the $\mathrm{z}$ value of Sobel's test was calculated using the guidelines of Soper (Soper, 2019). The $\mathrm{z}$ value was calculated using the formula: $\left(\frac{a * b}{\sqrt{b^{2}} * \mathrm{SE}_{a}^{2}+a^{2} * \mathrm{SE}_{b}^{2}}\right)$, where SE is the standard error. Variance Accounted For (VAF) determined the mediation size effect. VAF was calculated by Hair guidelines (Hair et al., 2017), using the formula: $\%\left(\frac{a * b}{(a * b+d)}\right)$. 'VAF 
Table 6. Mediation test results

\begin{tabular}{|c|c|c|c|}
\hline Mediation Analysis (NS $\rightarrow$ BI) & Standard Beta $(\beta)$ & STDEV & $t$-Value \\
\hline \multicolumn{4}{|c|}{ Model 1 (Mediation of Attitude): NS $\rightarrow$ AT $\rightarrow$ BI } \\
\hline $\mathrm{NS} \rightarrow$ AT (a) & $0.79^{*}$ & 0.03 & 35.87 \\
\hline $\mathrm{AT} \rightarrow \mathrm{BI}(\mathrm{b})$ & $0.78^{*}$ & 0.07 & 35.73 \\
\hline $\mathrm{NS} \rightarrow \mathrm{BI}(\mathrm{c})$ without mediator & $0.52^{*}$ & 0.04 & 21.56 \\
\hline $\mathrm{NS} \rightarrow \mathrm{BI}(\mathrm{d})$ with mediator & $0.44^{*}$ & 0.08 & 17.97 \\
\hline \multicolumn{4}{|c|}{ Model 2 (Mediation of Social Norms): $\mathrm{NS} \rightarrow \mathrm{SN} \rightarrow \mathrm{BI}$} \\
\hline $\mathrm{NS} \rightarrow \mathrm{SN}(\mathrm{a})$ & $0.68^{*}$ & 0.09 & 28.11 \\
\hline $\mathrm{SN} \rightarrow \mathrm{BI}(\mathrm{b})$ & $0.58^{*}$ & 0.07 & 22.13 \\
\hline $\mathrm{NS} \rightarrow \mathrm{BI}(\mathrm{c})$ without mediator & $0.52^{*}$ & 0.06 & 21.56 \\
\hline $\mathrm{NS} \rightarrow \mathrm{BI}(\mathrm{d})$ with mediator & $0.37^{*}$ & 0.04 & 15.97 \\
\hline \multicolumn{4}{|c|}{ Model 3 (Mediation of Perceived Behavioral Control): NS $\rightarrow \mathrm{PBC} \rightarrow \mathrm{BI}$} \\
\hline $\mathrm{NS} \rightarrow \mathrm{PBC}(\mathrm{a})$ & $0.71^{*}$ & 0.06 & 29.71 \\
\hline $\mathrm{PBC} \rightarrow \mathrm{BI}(\mathrm{b})$ & $0.67^{*}$ & 0.02 & 27.83 \\
\hline $\mathrm{NS} \rightarrow \mathrm{BI}(\mathrm{c})$ without mediator & $0.52^{*}$ & 0.11 & 21.56 \\
\hline $\mathrm{NS} \rightarrow \mathrm{BI}(\mathrm{d})$ with mediator & $0.41^{*}$ & 0.08 & 16.51 \\
\hline Mediation Analysis (NF $\rightarrow$ BI) & Standard Beta $(\beta)$ & STDEV & $t$-Value \\
\hline \multicolumn{4}{|c|}{ Model 4 (Mediation of Attitude): $\mathrm{NF} \rightarrow \mathrm{AT} \rightarrow \mathrm{BI}$} \\
\hline $\mathrm{NF} \rightarrow \mathrm{AT}(\mathrm{a})$ & $0.59^{*}$ & 0.01 & 22.57 \\
\hline $\mathrm{AT} \rightarrow \mathrm{BI}(\mathrm{b})$ & $0.72^{*}$ & 0.03 & 30.13 \\
\hline $\mathrm{NF} \rightarrow \mathrm{BI}(\mathrm{c})$ without mediator & $0.34^{*}$ & 0.04 & 14.09 \\
\hline $\mathrm{NF} \rightarrow \mathrm{BI}(\mathrm{d})$ with mediator & $0.32^{*}$ & 0.07 & 13.71 \\
\hline \multicolumn{4}{|c|}{ Model 5 (Mediation of Social Norms): $\mathrm{NF} \rightarrow \mathrm{SN} \rightarrow \mathrm{BI}$} \\
\hline $\mathrm{NF} \rightarrow \mathrm{SN}(\mathrm{a})$ & $0.51^{*}$ & 0.09 & 21.31 \\
\hline $\mathrm{SN} \rightarrow \mathrm{BI}(\mathrm{b})$ & $0.65^{*}$ & 0.01 & 27.08 \\
\hline $\mathrm{NF} \rightarrow \mathrm{BI}(\mathrm{c})$ without mediator & $0.34^{*}$ & 0.07 & 14.09 \\
\hline $\mathrm{NF} \rightarrow \mathrm{BI}(\mathrm{d})$ with mediator & $0.29^{*}$ & 0.07 & 12.89 \\
\hline \multicolumn{4}{|c|}{ Model 6 (Mediation of Perceived Behavioral Control): $\mathrm{NF} \rightarrow \mathrm{PBC} \rightarrow \mathrm{BI}$} \\
\hline $\mathrm{NF} \rightarrow \mathrm{PBC}(\mathrm{a})$ & $0.67^{*}$ & 0.07 & 27.83 \\
\hline $\mathrm{PBC} \rightarrow \mathrm{BI}(\mathrm{b})$ & $0.66^{*}$ & 0.01 & 27.68 \\
\hline $\mathrm{NF} \rightarrow \mathrm{BI}(\mathrm{c})$ without mediator & $0.34^{*}$ & 0.09 & 14.09 \\
\hline $\mathrm{NF} \rightarrow \mathrm{BI}(\mathrm{d})$ with mediator & $0.31^{*}$ & 0.09 & 17.51 \\
\hline \multicolumn{4}{|c|}{ Preacher and Hayes's (2008): Bootstrapping for Specific Indirect Effects } \\
\hline MODEL & Standard Beta $(\beta)$ & STDEV & $t$-Value \\
\hline Model-1: NS $\rightarrow$ AT $\rightarrow \mathrm{BI}$ & $0.34^{*}$ & 0.11 & 14.04 \\
\hline Model-2: NS $\rightarrow \mathrm{SN} \rightarrow \mathrm{BI}$ & $0.22^{*}$ & 0.09 & 9.12 \\
\hline Model-3: NS $\rightarrow \mathrm{PBC} \rightarrow \mathrm{BI}$ & $0.26^{*}$ & 0.17 & 10.28 \\
\hline Model-4: NF $\rightarrow$ AT $\rightarrow$ BI & $0.28^{*}$ & 0.18 & 11.14 \\
\hline Model-5: NF $\rightarrow \mathrm{SN} \rightarrow \mathrm{BI}$ & $0.19^{*}$ & 0.17 & 8.08 \\
\hline Model-6: NF $\rightarrow$ PBC $\rightarrow$ BI & $0.27^{*}$ & 0.16 & 10.51 \\
\hline \multicolumn{4}{|l|}{ Test for Mediation (Sobel, 1982) } \\
\hline MODEL & \multicolumn{3}{|c|}{ z-values } \\
\hline Model-1: NS $\rightarrow$ AT $\rightarrow$ BI & \multicolumn{3}{|l|}{$5.27^{*}$} \\
\hline Model-2: NS $\rightarrow \mathrm{SN} \rightarrow \mathrm{BI}$ & \multicolumn{3}{|l|}{$3.86^{*}$} \\
\hline Model-3: NS $\rightarrow$ PBC $\rightarrow$ BI & \multicolumn{3}{|l|}{$4.38^{*}$} \\
\hline
\end{tabular}




\begin{tabular}{|c|c|c|}
\hline Model-4: $\mathrm{NF} \rightarrow \mathrm{AT} \rightarrow \mathrm{BI}$ & $3.99^{*}$ & \\
\hline Model-5: NF $\rightarrow \mathrm{SN} \rightarrow \mathrm{BI}$ & $3.18^{*}$ & \\
\hline Model-6: NF $\rightarrow$ PBC $\rightarrow$ BI & $4.08^{*}$ & \\
\hline \multicolumn{3}{|c|}{ Mediation Effects Size (Hair et al., 2017) } \\
\hline MODEL & VAF (Aprox) & Size \\
\hline Model-1: NS $\rightarrow$ AT $\rightarrow$ BI & 58 & Partial \\
\hline Model-2: NS $\rightarrow \mathrm{SN} \rightarrow \mathrm{BI}$ & 52 & Partial \\
\hline Model-3: NS $\rightarrow$ PBC $\rightarrow$ BI & 50 & Partial \\
\hline Model-4: NF $\rightarrow$ AT $\rightarrow \mathrm{BI}$ & 57 & Partial \\
\hline Model-5: $\mathrm{NF} \rightarrow \mathrm{SN} \rightarrow \mathrm{BI}$ & 53 & Partial \\
\hline Model-6: NF $\rightarrow$ PBC $\rightarrow$ BI & 57 & Partial \\
\hline
\end{tabular}

\%' value specifies the ratio of an indirect effect to total effect. The detailed results are presented in Table 6.

As shown in the Table 6 , for model-1 (i.e. NS $\rightarrow \mathrm{AT} \rightarrow \mathrm{BI}$ ), need satisfaction is found as a positive significant predictor of behavioral intention ( $\beta=0.44$; $t$-value $=17.97 ; \mathrm{p}<0.01$ ). In addition, attitude as a proposed mediator has positive significant impact on $\mathrm{BI}(\beta=0.72 ; t$-value $=30.13$; $\mathrm{p}<0.01)$. Sobel's (1982) test result for the indirect effect of NS on BI is also found positive and significant $(\mathrm{z}=5.27 ; \mathrm{p}<0.01)$. Further, the bootstrapping results revealed no zero in the range [lower, upper] of the confidence interval. Hence, all the mediation conditions between NS and BI are satisfied (Farooq \& Salam, 2020; Preacher \& Hayes, 2008). So, hypothesis H4a is reconfirmed. Similarly, for model-2 (i.e. NS $\rightarrow \mathrm{SN} \rightarrow$ $\mathrm{BI})$, NS has found to have a significant and positive impact on $\mathrm{BI}$ ( $\beta=0.37 ; t$ value $=15.97 ; \mathrm{p}<0.01)$. The proposed mediator subjective norms has a positive and significant impact on BI ( $\beta=0.58 ; t$-value $=22.13 ; p<0.01)$. Sobel's (1982) test for assessing the indirect effect of NS on BI is also found positive and satisfactory $(\mathrm{z}=3.86 ; \mathrm{p}<0.01)$. In addition to the above, the bootstrapping results revealed no zero in the range [lower, upper] of the confidence interval. Hence, a significant and positive mediation of SN between NS and $\mathrm{BI}$ is found true. So, hypothesis $\mathrm{H} 4 \mathrm{~b}$ is reconfirmed. Likewise, for model 3 (i.e. NS $\rightarrow \mathrm{PBC} \rightarrow \mathrm{BI}$ ), NS is positively and significantly linked to $\mathrm{BI}(\beta=0.41 ; t$-value $=16.51 ; \mathrm{p}<0.01)$. The proposed mediator perceived behaviour control positively and significantly impacted BI ( $\beta=0.67 ; t$-value $=27.83$; $\mathrm{p}<0.01)$. Sobel's (1982) test for assessing the indirect effect of NS on BI is also found positive and satisfactory $(\mathrm{z}=4.38 ; \mathrm{p}<0.01)$. Further, the bootstrapping results revealed no zero in the range [lower, upper] of the confidence interval. Henceforth, the significant and positive mediation of PBC between NS and BI is found satisfactory. So, hypothesis $\mathrm{H} 4 \mathrm{c}$ is reconfirmed. Similarly, the impact of mediation of AT, SN, and PBC between need frustration and behaviour intention are observed using model $(4,5 \& 6)$, and the results are also presented in Table 6. Reported results confirm a significant and positive mediating effect of AT, SN and PBC on the relationship between NF and BI. Hence the hypothesis (H5a, H5b and $\mathrm{H} 5 \mathrm{c}$ ) are reconfirmed.

Even though the above results established the significant mediation effect of all the proposed mediators in the mul- tiple parallel mediator models, however, the actual size of mediation (i.e. full or partial) is essential to analyze the mediation impact. Hence VAF \% (i.e. Variance Accounted For) was used to estimate the size of the indirect effect of mediator in multiple mediator models (Hair et al., 2017). Generally, VAF value is grouped into three different categories, i.e. $\mathrm{VAF}<20 \%$ : no mediation; $20 \% \leqslant \mathrm{VAF} \geqslant 80 \%$ : partial mediation; VAF >80\%: full mediation (Hair et al., 2017). As shown in Table 6 for model 1, the VAF \% value is $58 \%$, which means that the indirect effect explains $58 \%$ of the total effect of NS on BI (i.e. in model 1). Hence attitude (AT) is partially mediating the relation NS $\rightarrow$ BI. Similarly, the results presented in Table 6 confirm the partial mediation for all the other models (i.e. 2, 3, 4, 5, and 6). However, the finding is also revealed that the mediation effect of attitude to owned business is stronger than that of the SN and PBC. Hence, all the findings reported above offer deep insight into restaurant owners' motivational factors towards predicting the intention to sustain the business via attitude, subjective norms and perceived behavioural control in India after COVID-19 lockdown.

\section{Discussion}

Understanding the motivational and social cognitive factors to promote the entrepreneurial behaviours among restaurant owners during and after the post-COVID-19 lockdown situation is crucial to all the stakeholders. Therefore, a comprehensive, unified model using well-established social cognitive and motivational theories (SDT and TPB) was adopted in this research. Precisely, this study was aimed at exploring the role of the need motivation on facilitating and explaining the restaurant owners' behavioural intention towards sustaining their business after the COVID-19 lockdown in India. Furthermore, this study investigates the mediating role of $\mathrm{AT}, \mathrm{SN}$, and $\mathrm{PBC}$ in the relationship between need factors (NS \& NF) and BI. The integration of the TPB and SDT helps to provide comprehensive explanations of the role of need motivation in planned behavioural Intention (Hagger \& Chatzisarantis, 2009; Liao \& Fang, 2019; Roca \& Gagné, 2008; Suen et al., 2020).

Overall, the findings reported in this research support the argument that the need satisfaction and need frustration play a significant role in predicting behavioural inten- 
tion, where $68 \%$ of the variance in BI has been explained by the proposed variables (Table 4 ). One of the most relevant results reported in this study is the confirmation of intrinsic (NS) and extrinsic (NF) motivations as a predictor of future entrepreneurial planning and the intention to sustain the business after the COVID-19 lockdown. Further, the results show a negative correlation between NS and NF. This indicates that NS and NF are partially opposing each other. That means individuals with high intrinsic motivation towards the business will generally indicate low extrinsic motivations and vice-versa (Al-Jubari, 2019).

The study results have shown that AT, SN and PBC are the significant antecedents of BI. Furthermore, an intrinsic motivational construct of SDT (i.e. NS) has significantly impacted the proximal TPB constructs (AT, SN, and PBC). Several past studies have also reported similar results (AlJubari, 2019; Hagger \& Chatzisarantis, 2009). Theoretically, the results of this study have strengthened the justification of SDT \& TPB integration. Further, the findings of this study confirm that the intrinsic motivation factor (NS) has a significant effect on the restaurant owners' attitudes, norms, and control perceptions. Intrinsic motivation helps entrepreneurs be more persistent and demonstrate more effective performance in their business (Al-Jubari, 2019; Deci \& Ryan, 2012). Thus, the intrinsic motivations could help enhance the restaurant owners' intention to continue with their business even after a lot of hardship during COVID-19.

Furthermore, as a consequence of intrinsic motivation, there will be a brighter chance of transformation from intention to actual action among these entrepreneurs. These intrinsically motivated restaurant owners will sustain their business even in COVID-19 like future situations and will accordingly be less likely to give up their business. In this sense, the sustaining ratio to continue with entrepreneurial activities should be higher. Similarly, their performance after COVID lockdown would also be higher due to their higher commitment, persistence, and extended support from the social and political environment (Deb \& Wiklund, 2017). Restaurant owners, whose psychosocial needs are supported by the social and political environment, would have favourable perceptions and intention to sustain their business after COVID-19 lockdown due to a sense of promise from the environment and the motivation originates from their inner self. The study results are also revealed that restaurant owners to continue with the same business have derived from their experience to handle different challenging tasks during difficult times of COVID-19, and they can effectively act upon it even in post-COVID-19 lockdown.

On the other hand, extrinsic motivation focuses more on instant outputs. Generally, it is assumed that behavioural intention towards entrepreneurship may be diluted in the face of obstacles and hardship. Therefore, entrepreneurs are more likely to abandon their nascent behaviours due to adverse situations. But the findings of this study have shown that the need-frustration leads to higher intention. Several studies have reported similar findings (Al-Jubari, 2019; Weinstein \& Ryan, 2011). But, after the COVID-19 lockdown, the restaurant owners' extrinsic motivation will probably focus on the external booties (incomes, sales, etc.). If they don't receive the rewards as expected, they will probably discontinue the venture by closing it down or selling it. The above arguments seem very tentative against the results obtained from this research. Even the restaurant owners have faced many difficulties managing their business resources during the COVID-19 lockdown. Still, they are optimistic about the supports for their communities, family $\&$ friends, and governmental policies to optimize their outcomes. Recently the government of India has announced an economic stimulus package of twenty-lakh-crore to support the COVID-19 hit people and ventures. This announcement has given a boost to their extrinsic motivation. This was observed from our team's conversation with different restaurant owners during the data collection phase. Again, the mediation of cognitive factors seems to have influenced to achieve a strong positive relation between need frustration and intention to sustain their business. In addition to the above discussion, it was also observed in various studies that need frustration also links to the presence of mental disorders and may adversely impact the Intention (Teixeira et al., 2018). On the contrary, some researchers have found that people with mental disorders are often successful venture creators (Wiklund et al., 2019). That means the previous studies have also supported the positive influence of need frustration on intention. In other words, in the presence of an unsupportive and demanding environment during COVID-19, the need for frustration may help them develop a personality that would lead them to form assertive entrepreneurial behaviour in the future.

To summarize the discussion, it can be noted that all the hypotheses formulated in this study are satisfied, which highlight the usefulness of the chosen constructs and their associations that have an impact on the prediction of behavioural intention. Precisely, starting from the consideration of the SDT constructs and the mediating role of TPB construct to predict intention are well supported by previous studies (Lorna et al., 2020; Chunxiao \& Yandan, 2019; Al-Jubari, 2019; Liñán and Fayolle, 2015; Fayolle et al., 2014)

\subsection{The implication of the Study}

The study has both practical and theoretical implications. The finding of this study can lead the academicians and practitioners to consider this study as a potential tool to investigate further the theoretical and managerial implications in hospitality management and entrepreneurship.

\section{Theoretical Contribution}

This study addressed the need to integrate motivational theory (SDT) and social cognitive theory (TPB) for methodological enhancements. The study's findings corroborated the solidity of the theoretical models (SDT and TPB) developed by different researchers (Ajzen, 2011; Ryan \& Deci, 2000). The findings of this study may help to enrich the literature related to the antecedents causing human behavioural intentions. Apart from the above, this study also makes two significant contributions to the existing literature. First, this study supports the arguments that intention can only be better predicted by its proximal cognitive factors, e.g. AT, SN and PBC (Ajzen, 1991; Al-Jubari, 2019; Li \& $\mathrm{Wu}, 2019$; Suen et al., 2020). Second, the study has also jus- 
tified the usefulness of Need motivational factors (NS and $\mathrm{NF}$ ) to explain the intention to continue with the business and the mediating role of AT, SN, and PBC (Al-Jubari, 2019).

\section{Managerial Implication}

The study could benefit all those who want to study people's behavioural intention in an adverse situation like the COVID-19 pandemic. This study may help cultivate a deeper understanding of the entrepreneurial motivational and cognitive factors contributing to predicting behavioural intention towards engagement in entrepreneurial activities (Becherer et al., 2005). These empirical findings may also help and guide all the stakeholders in identifying the critical factors to sustain the business during and after the COVID-19 pandemic like situation. For example, in terms of motivation (intrinsic or extrinsic), all necessary steps may be taken to boost their confidence, enhancing their intention to sustain the business.

\section{Conclusion and Future Scope}

To conclude, this study has tried to justify applying an integrated theoretical framework using appropriate cognitive constructs and need motivational constructs in understanding the restaurant owners' entrepreneurial intention to continue with their business after the COVID-19 lockdown in India. This study also has offered interesting results and analysis on which all the stakeholders concerning hospitality industries should reflect. In particular, the finding would be helpful for government policymakers and other agencies to implement policies, which can help restaurant owners to sustain their business after the
COVID-19 pandemic. Furthermore, considering the structural equation model as a tool makes it possible to effectively test all the formulated hypotheses in a complex theoretical model involving simultaneous parallel mediation. Furthermore, the proposed theoretical model in this study has been empirically evaluated using a pretty large sample (more than 500 responses) that makes the findings more generalizable.

Finally, it is worth mentioning that this work also has limitations like any other study. First, even though the use of the questionnaire helped in data collection and analysis; but, it did not allow us to deeply understand why negative motivational factors like need frustration have a strong positive association with intention. A qualitative researchbased approach (such as in-depth interviews) may be appropriate in the future to overcome this limitation. Similarly, the current study sample was restricted only to central India. Nonetheless, the motivational factors considered in this study (need satisfaction or frustration) are related mainly to peoples social expectations. Hence, different cultures and individualities may probably influence these motivations. Therefore, future research should simultaneously replicate this study in other parts of India or even in several countries. Last but not least, the future study should also consider the multi-group analysis involving different social and demographic characteristics (e.g. size of the business, gender, age, experience, etc.) to generalize the findings further.

Submitted: July 19, 2021 CST, Accepted: January 21, 2022 CST 


\section{REFERENCES}

Ajzen, I. (1991). The theory of planned behavior. Organizational Behavior and Human Decision Processes, 50(2), 179-211.

Ajzen, I. (2011). The theory of planned behaviour: Reactions and reflections. In Psychology \& health (Vol. 26, Issue 9, pp. 1113-1127). Taylor \& Francis.

Al-Jubari, I. (2019). College students' entrepreneurial intention: Testing an integrated model of SDT and TPB. Sage Open, 9(2), 2158244019853467.

Almobaireek, W. N., \& Manolova, T. S. (2012). Who wants to be an entrepreneur? Entrepreneurial intentions among Saudi university students. African Journal of Business Management, 6(11), 4029-4040.

Alolah, T., Stewart, R. A., Panuwatwanich, K., \& Mohamed, S. (2014). Determining the causal relationships among balanced scorecard perspectives on school safety performance: Case of Saudi Arabia. Accident Analysis \& Prevention, 68, 57-74.

Andersen, S. M., Chen, S., \& Carter, C. (2000). Fundamental human needs: Making social cognition relevant. Psychological Inquiry, 11(4), 269-275.

Armstrong, J. S., \& Overton, T. S. (1977). Estimating nonresponse bias in mail surveys. Journal of Marketing Research, 14(3), 396-402.

Barkoukis, V., Hagger, M. S., Lambropoulos, G., \& Tsorbatzoudis, H. (2010). Extending the transcontextual model in physical education and leisuretime contexts: Examining the role of basic psychological need satisfaction. British Journal of Educational Psychology, 80(4), 647-670.

Becherer, R. C., Finch, J. H., \& Helms, M. M. (2005). The influences of entrepreneurial motivation and new business acquisition on strategic decision making. Journal of Small Business Strategy, 16(2), 1-14.

Cardella, G. M., Hernández-Sánchez, B. R., \& SánchezGarcía, J. C. (2020). Basic psychological needs as a motivational competence: Examining validity and measurement invariance of Spanish BPNSF scale. Sustainability, 12(13), 5422.

Chaulagain, S., Pizam, A., \& Wang, Y. (2021). An integrated behavioral model for medical tourism: An American perspective. Journal of Travel Research, 60(4), 761-778.

Chen, B., Vansteenkiste, M., Beyers, W., Boone, L., Deci, E. L., Van der Kaap-Deeder, J., Duriez, B., Lens, W., Matos, L., Mouratidis, A., \& others. (2015). Basic psychological need satisfaction, need frustration, and need strength across four cultures. Motivation and Emotion, 39(2), 216-236.

Creswell, J. W., \& Creswell, J. D. (2017). Research design: Qualitative, quantitative, and mixed methods approaches. Sage publications.

Deb, P., \& Wiklund, J. (2017). The effects of CEO founder status and stock ownership on entrepreneurial orientation in small firms. Journal of Small Business Management, 55(1), 32-55.
Deci, E. L., \& Ryan, R. M. (1985). Motivation and selfdetermination in human behavior. NY: Plenum Publishing Co.

Deci, E. L., \& Ryan, R. M. (2000). The" what" and" why" of goal pursuits: Human needs and the selfdetermination of behavior. Psychological Inquiry, 11(4), 227-268.

Deci, E. L., \& Ryan, R. M. (2012). Self-determination theory in health care and its relations to motivational interviewing: a few comments. International Journal of Behavioral Nutrition and Physical Activity, 9(1), 1-6.

Fachrunnisa, O., Adhiatma, A., Lukman, N., \& Ab Majid, M. N. (2020). Towards SMEs' digital transformation: The role of agile leadership and strategic flexibility. Journal of Small Business Strategy, 30(3), 65-85.

Farooq, M. S., \& Salam, M. (2020). Nexus between CSR and DSIW: a PLS-SEM approach. International Journal of Hospitality Management, 86, 102437.

Fayolle, A., Liñán, F., \& Moriano, J. A. (2014). Beyond entrepreneurial intentions: values and motivations in entrepreneurship. International Entrepreneurship and Management Journal, 10(4), 679-689.

Fregetto, E. (2015). INVESTIGATING THE IMPACT OF A SMALL BUSINESS CONSULTING COURSEON ENTREPRENEURIAL ATTITUDES. Journal of Small Business Strategy, 25(1).

Hagger, M. S., \& Chatzisarantis, N. L. (2009). Integrating the theory of planned behaviour and selfdetermination theory in health behaviour: A metaanalysis. British Journal of Health Psychology, 14(2), 275-302.

Hair, J. F., Anderson, R. E., Babin, B. J., \& Black, W. C. (2010). Multivariate data analysis: A global perspective (Vol. 7). Upper Saddle River, NJ: Pearson.

Hair, J. F., Jr, Sarstedt, M., Ringle, C. M., \& Gudergan, S. P. (2017). Advanced issues in partial least squares structural equation modeling. saGe publications.

Harman, H. H. (1976). Modern factor analysis. University of Chicago press.

Henseler, J., Ringle, C. M., \& Sinkovics, R. R. (2009). The use of partial least squares path modeling in international marketing. In New challenges to international marketing. Emerald Group Publishing Limited.

Iakovleva, T., \& Kolvereid, L. (2009). An integrated model of entrepreneurial intentions. International Journal of Business and Globalisation, 3(1), 66-80.

Kautonen, T., Van Gelderen, M., \& Tornikoski, E. T. (2013). Predicting entrepreneurial behaviour: a test of the theory of planned behaviour. Applied Economics, 45(6), 697-707.

Kim, Jaewook, Kim, J., Lee, S. K., \& Tang, L. R. (2020). Effects of epidemic disease outbreaks on financial performance of restaurants: Event study method approach. Journal of Hospitality and Tourism Management, 43, 32-41. 
Kim, Jungkeun, \& Lee, J. C. (2020). Effects of COVID-19 on preferences for private dining facilities in restaurants. Journal of Hospitality and Tourism Management, 45, 67-70.

Li, C., \& Wu, Y. (2019). Understanding voluntary intentions within the theories of self-determination and planned behavior. Journal of Nonprofit \& Public Sector Marketing, 31(4), 378-389.

Liao, W.-L., \& Fang, C.-Y. (2019). Applying an extended theory of planned behavior for sustaining a landscape restaurant. Sustainability, 11(18), 5100.

Liñán, F., \& Chen, Y. (2009). Development and cross-cultural application of a specific instrument to measure entrepreneurial intentions. Entrepreneurship Theory and Practice, 33(3), 593-617.

Mehrotra, A. (2020). The Indian restaurant industry will never be the same. https://cio.economictimes.indiatim es.com/news/corporate-news/the-indian-restaurant-i ndustry-will-never-be-the-same/75157663(

Milyavskaya, M., \& Koestner, R. (2011). Psychological needs, motivation, and well-being: A test of selfdetermination theory across multiple domains. Personality and Individual Differences, 50(3), 387-391.

Moriano, J. A., Gorgievski, M., Laguna, M., Stephan, U., \& Zarafshani, K. (2012). A cross-cultural approach to understanding entrepreneurial intention. Journal of Career Development, 39(2), 162-185.

NRAI. (2020). National Restaurant Association of India. $\underline{\mathrm{h}}$ ttps://nrai.org/

Podsakoff, N. (2003). Common method biases in behavioral research: A critical review of the literature and recommended remedies. Journal of Applied Psychology, 885(879), 10-1037.

Preacher, K. J., \& Hayes, A. F. (2008). Asymptotic and resampling strategies for assessing and comparing indirect effects in multiple mediator models. Behavior Research Methods, 40(3), 879-891.

Radel, R., Pelletier, L., Pjevac, D., \& Cheval, B. (2017). The links between self-determined motivations and behavioral automaticity in a variety of real-life behaviors. Motivation and Emotion, 41(4), 443-454.

Rivera, M. A. (2020). Hitting the reset button for hospitality research in times of crisis: Covid19 and beyond. International Journal of Hospitality Management, 87, 102528.

Roca, J. C., \& Gagné, M. (2008). Understanding elearning continuance intention in the workplace: A self-determination theory perspective. Computers in Human Behavior, 24(4), 1585-1604.

Ryan, R. M., \& Deci, E. L. (2000). Self-determination theory and the facilitation of intrinsic motivation, social development, and well-being. American Psychologist, 55(1), 68.
Shin, Y. H., Im, J., Jung, S. E., \& Severt, K. (2018). The theory of planned behavior and the norm activation model approach to consumer behavior regarding organic menus. International Journal of Hospitality Management, 69, 21-29.

Sigala, M. (2020). Tourism and COVID-19: Impacts and implications for advancing and resetting industry and research. Journal of Business Research, 117, 312-321.

Singh, R., Chen, F., \& Wegener, D. T. (2014). The similarity-attraction link: Sequential versus parallel multiple-mediator models involving inferred attraction, respect, and positive affect. Basic and Applied Social Psychology, 36(4), 281-298.

Siu, W., \& Lo, E. S. (2013). Cultural contingency in the cognitive model of entrepreneurial intention. Entrepreneurship Theory and Practice, 37(2), 147-173.

Sobel, M. E. (1982). Asymptotic confidence intervals for indirect effects in structural equation models. Sociological Methodology, 13, 290-312.

Soper, D. (2019). Free Sobel Test Calculator for the Significance of Mediation - Free Statistics Calculators. Free Statistics Calculators Index. https://w ww.danielsoper.com/statcalc/calculator.aspx?id=31

Stone, M. (1974). Cross-validatory choice and assessment of statistical predictions. Journal of the Royal Statistical Society: Series B (Methodological), 36(2), 111-133.

Suen, L. K. P., Siu, J. Y., Lee, Y. M., \& Chan, E. A. (2020). Knowledge level and motivation of Hong Kong young adults towards blood donation: a cross-sectional survey. BMJ Open, 10(1), e031865.

Teixeira, D. S., Silva, M. N., \& Palmeira, A. L. (2018). How does frustration make you feel? A motivational analysis in exercise context. Motivation and Emotion, 42(3), 419-428.

Thompson, E. R. (2009). Individual entrepreneurial intent: Construct clarification and development of an internationally reliable metric. Entrepreneurship Theory and Practice, 33(3), 669-694.

Van den Broeck, A., Vansteenkiste, M., De Witte, H., \& Lens, W. (2008). Explaining the relationships between job characteristics, burnout, and engagement: The role of basic psychological need satisfaction. Work \& Stress, 22(3), 277-294.

Weinstein, N., \& Ryan, R. M. (2011). A selfdetermination theory approach to understanding stress incursion and responses. Stress and Health, 27(1), 4-17.

Wiklund, J., Nikolaev, B., Shir, N., Foo, M.-D., \& Bradley, S. (2019). Entrepreneurship and well-being: Past, present, and future. Journal of Business Venturing, 34(4), 579-588. 